\title{
Lob der Fünfprozenthürde
}

verfassungsblog.de/lob-fuenfprozenthuerde/

Christoph Schönberger Fr 27 Sep 2013

Fr 27 Sep

2013

Die Fünf-Prozent-Hürde gehört zum Inventar der Bundesrepublik wie die FDP. Nach der Bundestagswahl vom 22. September, so will es scheinen, könnten diese alten Bekannten bald schon beide im Bonner Haus der bundesdeutschen Geschichte ihre letzte Ruhestätte finden, neben der Strickjacke Helmut Kohls. Seit FDP und AfD sehr knapp an der Sperrklausel scheiterten, seit 15 Prozent der abgegebenen Stimmen auf Parteien entfielen, die den Sprung in den Bundestag verfehlten, ist die Klausel neu in die Kritik geraten. Ihre Gegner geißeln sie als undemokratisches Hemmnis, als Maginot-Linie der etablierten Parteien gegenüber den vielfältigen politischen Strömungen in der deutschen Gesellschaft. Sie rufen nach dem Aggiornamento eines politischen Systems, das in der Tat oft überbehütet und stickig daherkommt.

Im Verfassungsrecht ist der Boden für diese Kritik längst bereitet. Das Bundesverfassungsgericht hat seine Ausdeutung der Wahlrechtsgleichheit unter den Bedingungen des Verhältniswahlrechts schon seit einiger Zeit mit deutscher Gründlichkeit radikalisiert. Das gipfelte in der Verwerfung der Fünf-Prozent-Hürde für die deutsche Europawahl in seiner Entscheidung aus dem Jahr 2011. Vor dem Wahlrecht zu den deutschen Landtagen und dem Deutschen Bundestag hat das Gericht freilich bisher Halt gemacht und die Klausel für die Bundestagswahl vor allem mit der Aufgabe begründet, stabile Regierungen zu bilden. Das muss nicht so bleiben. Verschiebungen im Parteiensystem und Änderungen des Wahlverhaltens könnten dem Gericht als Grundlage dienen, auch hier einen Positionswechsel zu vollziehen.

Wäre das politisch und demokratietheoretisch sinnvoll oder gar verfassungsrechtlich geboten? Die Antwort ist ein klares Nein. Das ist bereits ein schlichtes Gebot politischer Klugheit. Was über lange Jahrzehnte zur hohen Stabilität des bundesdeutschen politischen Systems beigetragen hat, darf man nicht unter dem Eindruck einer einzelnen Bundestagswahl zum alten Eisen werfen. Das Wahlrecht ist in den letzten Jahren schon zu vielen nur halb bedachten Änderungen ausgesetzt worden. Wahlsystem und Wahlverhalten stehen in vielfältigen Wechselbeziehungen zueinander; deshalb muss gerade das Wahlrecht äußerst behutsam gepflegt und fortentwickelt werden.

Das Wahlergebnis vom 22. September spricht auch gerade nicht für die These, die bundesdeutschen Altparteien hätten sich hinter der Klausel eingraben und verschanzen können. Wenn eine Traditionspartei wie die FDP die Hürde verfehlen, ein Neuling wie die AfD diese hingegen aus dem Stand fast überwinden kann, dann zeigt sich das Parteiensystem hier doch eher beweglich als starr und versteinert. Auch der Piratenpartei ist es gelungen, trotz der Sperrklausel in einzelne Landesparlamente zu gelangen. Das Gleiche hat sich in der Vergangenheit bei der Entstehung von Grünen und Linkspartei gezeigt. Es ist sicherlich richtig, dass die Sperrklausel einer neuen Partei einiges abverlangt. Aber einen closed shop errichtet sie heute weniger denn je.

Durchaus merkwürdig ist auch, dass die Klausel genau in dem Augenblick in die Kritik gerät, in dem sie ihren Zweck gerade erfüllt. Wenn das Parteiensystem diffuser wird, wenn vielfältige Kleinparteien in die Parlamente drängen, liegt genau die Konstellation vor, auf welche die Sperrklausel zugeschnitten ist. Die Klausel ermutigt nachdrücklich zur Konzentration des Parteiensystems. Die Stabilität, die das Parteiensystem im Deutschen Bundestag - der noch 1949 eher gewirkt hatte wie der letzte Reichstag der Weimarer Republik - in den fünziger Jahren rasch gewann, ist maßgeblich ihr Verdienst.

Sie mutet dem Wähler einer neuen oder kleinen Partei das Risiko zu, dass sich seine Stimme in der Zusammensetzung des Bundestages nicht niederschlägt. Sie tastet damit die Ernsthaftigkeit seines Anliegens ab und legt inm die nachdrückliche Selbstprüfung nahe, ob es für seine Überzeugung oder Interessenlage wirklich einer weiteren Partei im Parlament bedarf. Sie verlangt vom Wähler eine Stimmabgabe, die nicht allein höchstpersönliche Gesinnungen ausdrückt, sondern sich bereits in bescheidenem Maß einem Test auf ihre Verallgemeinerbarkeit unterzieht. Mit anderen Worten: Sie behandelt inn als Erwachsenen. 
konstitutionellen Monarchie haben wir die Leitidee geerbt, das Parlament müsse die Gesellschaft in ihrer ganzen Vielfalt und Buntheit getreulich darstellen und abbilden. Sie stammt aus den Zeiten, in denen das Parlament den herrschenden Monarchen und Bürokratien als Gegengewicht gegenübertrat. Selbstbewusste Bürger denken so nicht. Das Parlament hat nicht allein die Aufgabe, die Pluralität der Gesellschaft auszudrücken; es ist mindestens ebenso sehr der Ort, wo die Bürger durch ihre Repräsentanten zu gemeinsamen Regeln und Orientierungen kommen. Noch stärker ist diese Funktion, Gemeinsamkeit herzustellen, im parlamentarischen Regierungssystem, wo die Regierung auf die Unterstützung der Parlamentsmehrheit angewiesen ist. Der paradoxe Preis dafür, dass die Regierung vom Parlament abhängt, ist die Anleitung der Parlamentsmehrheit durch die Regierung.

Diesen Preis der demokratischen Selbstregierung zahlt man bei uns nicht gern. Vielmehr sehnt jede Gruppe, jedes Interesse sich danach, im Parlament so unverfälscht wie möglich abgebildet zu sein - ähnlich wie sie auch danach trachten, ihr jeweiliges Anliegen im Verfassungstext zur Sprache zu bringen. Das überfordert freilich das Parlament und führt umgekehrt zu der merkwürdigen Gewohnheit der allgemeinen Öffentlichkeit, fast nur die Stimmen in der öffentlichen Debatte teilnehmen zu lassen, die auch im Deutschen Bundestag Sitz und Stimme haben. Die Parlamentswahl fungiert als eine Art Platzanweisung für legitimes öffentliches Sprechen mit der Konsequenz, dass das Scheitern an der Fünf-Prozent-Hürde gleichzeitig die Unsichtbarkeit in der öffentlichen Diskussion bedeutet. Hier verbindet sich unsere alten korporatistischen Rituale sehr unglücklich mit den Weimarer Neurosen der bundesdeutschen Anfangsjahrzehnte.

Das eigentliche Problem ist nicht die Fünf-Prozent-Klausel, sondern die allzu starke Verdrängung randständiger Personen, Meinungen und Interessen aus der öffentlichen Debatte, zumal in den öffentlichrechtlichen Medien. Der Herauswurf Rainer Brüderles aus der Bonner Runde führte das noch am Abend der Bundestagswahl in aller Anschaulichkeit vor. Nun muss man die mediale Diskussion sicherlich nicht allein mit einer Vielzahl rechtsextremer Spinner, Computernerds oder eurokritischer Honoratioren auffüllen. Aber es würde der öffentlichen Debatte in der Bundesrepublik guttun, wenn sie einem breiteren Spektrum von Ansichten Raum gäbe, als es die Bundestagsparteien zum Ausdruck bringen können, und unorthodoxe Positionen nicht allein den Untiefen des Netzes überließe. Hier liegt der eigentliche Reformbedarf, und er betrifft die Debattenkultur der Gesellschaft insgesamt.

Wenn die öffentliche Debatte als allzu verriegelt erlebt wird, dann ist die Zugangshürde zum Parlament bei wachsender Pluralisierung der Meinungen und Orientierungen kaum noch erträglich. Es tritt dann der paradoxe Effekt ein, dass sofort in das Parlament hineindrängen muss, wer in der öffentlichen Debatte überhaupt vorkommen will. Die Fünf-Prozent-Klausel strukturiert und kanalisiert die spätere parlamentarische Willensbildung vor. Um so freier, offener und vielfältiger muss aber im Gegenzug die öffentliche Diskussion im vorparlamentarischen Raum sein. Die Zugangshürde verliert ihre demokratische Legitimität, wenn ihr angesonnen wird, zugleich Ideenpolizei des öffentlichen Raums zu sein. Wir brauchen beides: die Hürde und die Debatte!

LICENSED UNDER CC BY NC ND

SUGGESTED CITATION Schönberger, Christoph: Lob der Fünfprozenthürde, VerfBlog, 2013/9/27, http://verfassungsblog.de/lob-fuenfprozenthuerde/. 